\title{
An innovative research on autonomous learning ability's cultivation for the college students majoring in art design
}

\author{
Xin Guang REN ${ }^{1}$, Yong Min CUI ${ }^{1, a}$ \\ ${ }^{1}$ Rongcheng College,Harbin University of Science and Technology, Rongcheng;Shandong, China
}

\begin{abstract}
The autonomous learning ability plays an important role on the process of improving college or university students' comprehensive qualities. For the college students majoring in Art Design, this kind of ability can help them master the professional skills of art and design effectively and contribute to the improvement of comprehensive quality and professional attainment. This paper mainly puts forward some effective measures to improve the college students' autonomous learning ability through two ways: first, analyzing the problems during the process of forming the autonomous learning ability, which exists among the students majoring in Art Design; second, acknowledging the important meanings of cultivating this ability. These measures are conductive to the development of college students who study this major and their cultivation, and meeting the social demand for practical talents in this field.
\end{abstract}

With the rocketing development of the Internet science technology, the information from mass media such as WeChat, Microblog and so on updates more quickly than the information in textbooks. So Internet becomes an important approach when people obtain the new information day by day. It also makes up for the textbooks' deficiencies and is convenient for teachers to do a better teaching. For the college students majoring in Art Design, the cultivation of autonomous learning ability and its improvement have a vital effect on improving themselves comprehensive qualities. Therefore, the students majoring in Art Design should change their learning styles from the traditional infusion to autonomous learning and adapt to the new learning style. Students should make full use of the huge Internet resources and put the terminal such as Internet and mobile phone as a kind of learning media, besides to the school learning. College and university is not only the place to learn the professional knowledge but also a bridge from college to society. This period is the critical point for them to improve the self-restraint ability and the communicative ability. So for the college students majoring in Art Design, just studying in college is not enough. The knowledge acquiring from the traditional class and this kind of teachers are hard to meet the demand of society in this field. Then the cultivation of autonomous learning ability is of great importance for their study.

\section{The Problem of Autonomous Learning Ability Existing Among the Students Majoring in Art Design}

With the quickly development of economy and technology in China, design can meet people's aesthetic demand in their common life and then the art design industry has a rapid growth in the society. The college students majoring in Art Design can adopt flexible forms of employment and do various jobs related to the art design. Therefore, the high requirement of the art design personnel is made in the sustainable development aspect. The college and university should pay more attention on strengthening the cultivation of Art the Design majors' innovative abilities, especially their autonomous learning ability's cultivation and improvement.

\subsection{The Different Foundations of the College Students Whose Major are Art Design}

The Art Design Major is the combination of modern scientific technology and art. It has a high demand to the Art Design majors' comprehensive quality and needs to cultivate the overall design personnel who has good and professional aesthetic knowledge and a strong sense of art expressive ability. The difference of students' basic capabilities and study is a big obstacles which exist in the Art Design major's teaching process and the cultivation of autonomous learning ability. With the popularity of Chinese higher education and its growth, many high school students do badly in study respect and have little interest in the art, but they still chose the Art Design major as a shortcut to install college or university. In the result, some phenomena appear among the college students of this major, for example the different basic capabilities and study, the different learning attitude as well as the difficulty of students' management. In

\footnotetext{
$\bar{a}$ Yong Min Cui:renxinguang12@163.com
} 
addition, owing to the difference of students, many rural students are limited by their living standards and then they may lack of the experience of modern art design and the design foundation. Consequently, during the teaching practical activity of the Art Design major, the college or university should face the differences of professional foundations and backgrounds. They can do some organized activity to improve students' professional skills and knowledge' foundation in the art design aspect through building an integrated teaching system.

\subsection{The Serious Insufficient of Autonomous Learning Ability among the College Art Design Majors}

The college students of China accept the examinationoriented education in a long run and are accustomed to the passive learning style, especially the students whose major are Art Design. They lack of the autonomous learning ability through the learning style in high school and the mode of examination-oriented education. With the flourishing and growth of Chinese economy and society, the new skills, materials and the thoughts emerge as an endless stream. Being a modern art design worker, if autonomous learning ability is insufficient, that is to say, just learning through the passive learning style may lead to the loss of innovative and creative ability, it's hard to catch the pace of art design practice at last. The Art Design major is related to aesthetics, design, management, architecture, dress, media fields and so on. If the college students only attend to the teaching class, it is difficult to have the autonomous learning sense and build their own career planning accurately by themselves. Then they cannot have a comprehensive understanding related to the company and industry etc. and the problem of employment occurs with this problem during the graduation period.

\subsection{The Confusion during the Cultivation Process of Art Design Majors' Autonomous Learning Ability}

With the development and popularization of the Internet technology, the Internet has become an important way to accept new things for the ordinary people. Besides the textbooks and other books, there are several other cyber or practical ways for the college students whose major are Art Design to study in the autonomous learning style. For example, students need to design software, downloading can be used on the Internet; students need to design the material, searching on the Internet is a good way; students need to design originality things or thoughts, some reference on the Internet can be used etc... The network and computer bring students the sufficient resources and high work efficiency. However, at the same time, the students also can copying others ideas to finish their own works, which makes extensive learning style become a normality. In addition, the college students depend on the Internet deeply and it results in the some phenomena appearing universally, for instance, a serious shortage of professional art and design books reading quantity, professional learning not enough in depth and breadth and the lack of professional practice opportunities. Actually it makes students' autonomous learning channel single and is no use in training and improving their autonomous learning ability.

\section{The Important Meaning of Cultivating the Art Design Majors' Autonomous Learning Ability}

\subsection{Autonomous Learning Contributing to Inspiring Design Inspiration of the Art Design Major Students}

Design comes from life and in return it serves life. As to the college students majoring in Art Design, learning the professional knowledge is not only existing on their classroom, but also learning in anytime and anywhere. The traditional learning style cannot totally inspire students' inspiration in their professional field. The cultivation of design inspiration requires students to master a lot of information during daily study and common life by several ways, for example, reading books, searching on the Internet and so on. And thus students need to form a good habit of autonomous learning. The autonomous learning means they not only need to study the professional knowledge but also learning some knowledge related to humanities, art, science and technology etc. so that they can broaden their eyes and inspire the design inspiration.

Therefore, learning the professional course of art and design does not mean to meet the demand of the college students' comprehensive development in art and design aspects. The students must do the autonomous learning after class and be good at observing things, experience life, enhance the knowledge reserve and independent study ability so as to better stimulate their inspiration, create better works of art and design.

\subsection{Autonomous Learning Contributing to Developing the Art Design Majors' Creative Thinking}

During the design process of the Art Design majors, they need to expand the creative thinking of design through autonomous learning. Exploration, discovery, innovation are the strong power to the development of all disciplines. So, for the Art Design major in college and university, innovation is the soul of design creation. Because art covers many respects of people's common life, continuous innovation in the field of art and design makes all fields' communication possible in art and culture aspects. People like fresh things. So they are in the creation process of art and design. The static ideas tend to drain the origin of creation. So only through autonomous learning to dabble in different knowledge and absorb the useful things used for design from other fields can they continuously create the innovative works of art and design. Therefore, it is of great importance for 
the Art Design majors to cultivate autonomous learning ability.

\section{The Main Approach to Improve Art Design Majors' Autonomous Learning Ability}

\subsection{A Good Autonomous Learning Environment Created on Campus}

The environment of school can reflect the explicit or implicit features in the campus culture. It is a kind of cultural accumulation under some certain rules. The library in colleges or universities carries its cultural connotation and reveals the culture of the school in some extent. It is an important place for students to learn autonomously and plays an indispensable role on improving Art Design majors' autonomous learning ability. According to the needs related to teaching art and design professional knowledge, the library in colleges and universities should constantly update the professional books and resources, form the specialized characteristics database which can reflect the artistic design and pay more attention on the training of the information literacy among the students majoring in Art Design. Opening the art stacks in the library is convenient for the Art Design majors to look up and reference, and gives students a learning atmosphere to enrich themselves and keep their learning enthusiasm. Students can get abundant resources and services as well as study in a good learning atmosphere. The library truly has the effect of educating students to some extent.

Combined with the characteristics of the Art Design majors, the colleges or universities should make some regulations and rules in their management. Only making the scientific and overall systems can they avoid students' arbitrariness and subjectivity and use the rules to manage students' daily behaviors and learning attitudes so that making the students form a good learning style. Under the influence of good learning styles in class, even in the colleges or universities, the good habit of autonomous learning can be formed among the Art Design majors. Under the managing system in colleges, it is easy to neglect the communication with students under equality and freedom conditions and ignore the humanistic care for students. Consequently, administrators and teachers in colleges or universities should strengthen the communication with the students, respect the college students' personality characteristics, make efforts to find the human-centered factor in the process of the education and improve the students' autonomous learning ability.

Due to the emphasis on creative and practical ability of the Art Design major's characteristics, the college or university should make a relevant incentive mechanism to active and encourage the students' innovation and make efforts to launch various activities combined with the professional knowledge and specialized practice. For example, to establish a professional mentors studio related to visual communication design, environmental design and digital media art, to undertake some works based on the social actual projects, contributing to increasing the professional students' autonomous learning enthusiasm after class and guiding and helping students to run their own business; encouraging students to participate in the high level professional competition and its related professional and academic exchanges actively, making full use of social practice during their holiday and stimulating and training their autonomous learning ability in the practice. Colleges and universities establish the enterprise cooperation model with the enterprises to transmit Art Design majors to enterprises Dinggang internship, to practice their professional theory in the enterprises, to consolidate professional knowledge and to continuously test students' autonomous learning ability.

\subsection{Strengthening the Comprehensive Quality of Teachers and Helping to Guide Students' Autonomous Learning}

Improving the teachers' comprehensive quality and professional quality has a positive effect on the improvement of Art Design majors' autonomous learning. High level and high quality professional teachers of Art Design major tend to have a broad mind and wide vision, which does good to giving students a reasonable guide in the career planning. In order to improve the comprehensive qualities of teachers, teachers are required to innovate their teaching mode during the teaching process, so as to ensure to carrying out the teaching process efficiently, to cultivate the college students' autonomous learning ability and the ability of exploration actively. On the one hand, teachers should fully consider students' professional foundation and learning efficiency when they teach the students. With the aid of teaching materials and teaching equipment, teachers use lectures, exercises, questions and answers, to organize the discussion and guide the students to find the approaches of autonomous learning, and helping students master the professional knowledge. On the other hand, teachers should make good use of the network information, bring the new technology, new method and new ideas to their curriculum design and encourage students to study through searching professional material on the Internet. These behaviors can help students to keep up with the professional frontier, learn the new material and new concept etc. and also can stimulate the Art Design majors' learning motivation and interest and help students learning autonomously with the aid of the network.

In addition, the Art Design majors' cultural foundation is relatively weak in colleges and universities. They go their own way without discipline and have little attention on the learning planning and assessment. Besides guiding students in the class, teachers help them master the professional knowledge about art and design through the most effective way, and consciously improve students' autonomous learning ability through all kinds of approaches, so as to enable students to constantly improve the creative design ability, master the professional technology on the frontier as well as have 
the ability to adapt to the social needs and development. Therefore, teachers must enhance their life-long learning ability, constantly improve their own educational philosophy and improve the knowledge structure in order to make the professional education continue to meet to the social development demands in the new period.

\subsection{Stimulating Learning Motivation and Strengthening Students' Self-Monitoring Ability}

In order to make the Art Design majors cultivate autonomous learning ability, college administrators and teachers must inspire students' intrinsic professional learning motivation at first. In psychology, students are affected by many factors in their studying. However, the decisive factors is the students' learning motivation. Other inseparable factors contain the students' social value, learning interest, ability and consciousness etc... During their learning process, it is inevitably to encounter a variety of learning difficulties and then the learning motivation would gradually weaken. At this time it is particularly critical for the students to continue to adhere to the study by will. So, besides teaching knowledge in the classroom, teachers should pay more attention on guiding students, letting them understand the meanings and values of the professional courses and improving their teaching methods so as to leading the students to keep good curiosity and thirst for the professional knowledge which would help Art Design majors cultivating autonomous learning ability.

On the process of learning, the students not only need to have learning motivation and learning will but also have the scientific and rational planning during the autonomous learning. They need to have some selfmonitoring ability to overcome the inertia and avoid the blindly learning. Above all, the college students majoring in Art Design should do self-monitoring to develop a practical learning plan and objectives. On the same time the plan should consider their own actual situation. They need to adjust their plan in time by taking appropriate self-monitoring, continuous review and observing autonomous learning situation. Being Art Design majors in colleges and universities, upholding the long-term autonomous study plan can increase their autonomous learning ability and improve their professional skills. It can let them skilled use their knowledge and design skills and enhance their own employment power.

In short, the rapid development of the current knowledge and information society affects people's life style and the way of thinking. For the Art Design major's education and teaching work in Colleges and universities, it is necessary to break the traditional teaching style and innovate the teaching concept to deal with the great potential of the Art Design major's development in the information society. The cultivation of Art Design majors' autonomous learning ability can not only improve the students' comprehensive quality and professional quality, but also enhance their competitiveness of the future. Therefore, when the colleges and universities innovate teaching ideas in the
Art Design major, they also need to enhance the students' autonomous learning ability.

\section{References}

[1] Xiaoqing Li and Jianguo Li, The Improving Strategies of the Art Design Majors in Colleges or Universities [J], The Home of Drama, 2014. (18)

[2] Jiajia Xue. On the Improvement of the Fine Arts Majors' Autonomous Learning Ability in Colleges or Universities[J], Statistics and management, 2016. 1

[3] Min Yang and Hongjun Zhang, Analysis on How to Improve the Ability of Autonomous Learning Ability in the Art Voluntary School [J], The Age of Teaching, 2013. (23)

[4] Cheng Ji and Quan Wen,On the Cultivation and Innovation of the Autonomous Learning Ability [J], Literary Theory, 2015. (18)

[5] Xiaoquan Zeng, The Cultivation and Research on the Art Design Majors' Autonomous Learning Ability [J], The Higher Education Forum, 2010. 2

[6] Shifu Xu, A Study on the Environmental Art Design Major's Autonomous Learning Approaches under the Background of Internet [J], Educational Research on the Art, 2015. 9

[7] Zhi Liu, The Exploration on the Cultivation mode of the Art Design Majors' Autonomous innovative Ability [J],China Higher Education, 2014. (17) 